This is an author produced version of a paper published in Archives of Gerontology and Geriatric. This paper has been peer-reviewed but does not include the final publisher proof-corrections or journal pagination.

Citation for the published paper:

Stenzelius K, Westergren A, Mattiasson A, Hallberg IR.

" Older women and men with urinary symptoms."

Arch Gerontol Geriatr, 2005, Dec 26.

http://dx.doi.org/10.1016/j.archger.2005.11.001

Access to the published version may require journal subscription.

Published with permission from: Elsevier 


\section{OLDER WOMEN AND MEN WITH URINARY SYMPTOMS}

Karin Stenzelius ${ }^{a, b} *$

Albert Westergren ${ }^{a, c}$

Anders Mattiasson $^{b}$

Ingalill Rahm Hallberg ${ }^{c}$

${ }^{a}$ Department of Health Sciences, Faculty of Medicine, Lund University, P.O.Box: 157

SE-221 00 LUND, Sweden

${ }^{\mathrm{b}}$ Department of Urology, Lund University Hospital, SE-221 85 LUND, Sweden

${ }^{\mathrm{c}}$ The Vardal Institute, The Swedish Institute for Health Care Sciences, Lund University

P.O.Box: 187 SE-221 00 LUND, Sweden

${ }^{*}$ Corresponding authour:

e-mail: karin.stenzelius@med.lu.se

Tel: +46-46-2221977 Fax: +46-46-2221935 


\section{ABSTRACT}

The aim was to compare urinary symptoms and their influence on daily life among elderly $(75+)$ women and men in a sample that previously had reported difficulties controlling urine (UI) and/or other urinary symptoms (OU). A further aim was to find underlying structures of urinary symptoms and to identify symptoms which had an impact on seeking medical help and need of help in daily activities (dependency). Totally 771 (352 men and 419 women) over 75 years answered a questionnaire, addressed to those $(\mathrm{n}=1881)$ who in a previous population-based study had reported having symptoms of UI and/or OU using the Bristol Female Lower Urinary Tract Symptoms questionnaire (BF-LUTS) and International Continence Society male questionnaire (ICSmale).

The groups with UI, OU, women and men reported similar symptoms of frequency, day and night, as well as influence on social life, and avoidance of places and situations due to the urinary symptoms although they differed in storage and voiding symptoms. Feeling incomplete emptying of bladder differed between the UI, OU and mixed symptoms (MS) groups but not between gender. Of the whole sample $43.3 \%$ had sought medical help. Factor analysis of similar questions in BF-LUTS and ICSmale questionnaire resulted in the factors labelled voiding, storage, pain, frequency and daily life. Predictors of the urinary symptoms for needing help in daily activities were frequent micturition day and night (OR 3.2) when aged was controlled for. Influence on daily life (OR 2.5), storage symptoms (OR 2.2) and pain symptoms (OR 2.1) predicted seeking medical help. The results show that urinary symptoms are equally bothersome among men and women. There is a need to encourage elderly to seek medical help and to obtain treatment or alleviations for symptoms that give most bother and indicate dependency, such as frequent micturition day and night and difficulties to reach the toilet in time without leakage.

KEYWORDS: Aged, 75 and over, Lower urinary tract symptoms, Urinary incontinence, Gender, Dependency, Help seeking 


\section{INTRODUCTION}

Urinary symptoms among elderly persons affect daily life and may be one important factor for being in need of help from others or even residential care (Nakanishi et al., 1999). A Swedish agestratified study ( $\mathrm{n}=4278,75-105$ years) showed that $39 \%$ (31.2 to 55.8\%) reported urinary incontinence (UI) and $21 \%$ (13.6 to $30.2 \%)$ other urinary symptoms than incontinence (OU) (Stenzelius et al., 2004). The relatively high prevalence of all kinds of urinary symptoms in these ages among men and women show the need to identify and give priority to the urinary symptoms that have most effect on daily life and are most bothersome and/or related to dependency.

Incontinence, a storage symptom, is viewed as an isolated female problem, also in old age, although it is a problem among elderly men as well (Stenzelius et al., 2004). Storage symptoms such as incontinence are known to be more common among women and voiding symptoms such as weak stream and hesitance to void are known to be more common among men (Abrams et al., 1997; Stenzelius et al., 2004). However, storage symptoms are also quite common among elderly men and likewise voiding symptoms are quite common among elderly women (Stenzelius et al., 2004). An evaluation of urinary symptoms in a sample of Japanese patients $(n=550)$, men and women (range 40-92 years) showed that the prevalence of urinary problems was equally common in both sexes. The authors suggested that the ageing process of bladder seemed to be similar in men and women (Araki et al., 2003). As research has been sparse among the oldest old and among both sexes it is difficult to draw any conclusions on differences and similarities in urinary symptoms in these groups. All urinary symptoms should therefore be taken into account in research among older persons to be able to take gender differences into consideration.

Although questionnaires have been constructed to be used for either women or men, some studies have used the Bristol female LUTS questionnaire (BF-LUTS) or the Danish Prostatic Symptom 
score questionnaire (DAN-PSS) for both sexes and in younger populations, aged 20-70 and 4080 years respectively (Kay et al., 1999; Schatzl et al., 2000, 2001; Schmidbauer et al., 2001). These studies resulted in knowledge of symptom prevalence in both sexes in different ages, and they could thus enable conclusions to be drawn about differences and similarities among urinary symptoms in men and women in different age groups. For instance, nocturia was equally common among both sexes (Schatzl et al., 2000), women were more bothered by urinary symptom than men were (Kay et al., 1999) and differences between sexes in voiding and storage symptoms declined after the age of 60 (Schatzl et al., 2001). These studies show that similar questions can be used for both sexes and to provide knowledge about urinary symptoms and bother caused by symptoms among men and women.

Traditionally urinary symptoms are tested or measured by objective diagnostic tests and symptom severity is based on these results. However, these tests do not include the patient perspective, even though there is reported to be a poor relationship between the severity of symptoms and the patient's experience of bother (Wyman et al., 1987). There are questionnaires that have included questions about how much bother a symptom causes (Meyhoff et al., 1993; Hansen et al., 1995; Donovan et al., 1996; Jackson et al., 1996), although a scoring system that describes relations between the actual symptom and bother has not been developed (Meyhoff et al., 1993, Hansen et al., 1995, Donovan et al., 1996, Jackson et al., 1996). However, the approach of including a personal perspective is valuable as health care should devote most efforts to those symptoms which give most bother.

Incontinence has been reported to have an impact on need for help from others in activities of daily living (ADL) (Noelker, 1987). However, OU could also be of importance. No studies, to our knowledge, have compared the importance of all urinary symptoms for need of help in ADL, which includes personal (PADL i.e. eating, toileting, personal care) and instrumental activities of 
daily living (IADL, i.e. shopping, cleaning etc.). Differences in study designs make comparisons between those needing or not needing help in ADL difficult as they focus either on nursing home inhabitants (Ouslander et al., 1998; Aggazzotti et al., 2000), a group with large help needs, or on community-dwelling older persons, with less need of help (Maggi et al., 2001; Stoddart et al., 2001). Only with samples including older persons living in the community as well as residential care could such comparisons be possible. Knowledge of those urinary symptoms, which have strongest relation to dependency, could be helpful in developing interventions that would improve handling daily life without help in this private matter as long as possible.

It seems to be taboo to talk about symptoms from the urinary tract, which may influence whether older persons seek medical help. For instance, few (38-57\%) of the older persons suffering from incontinence sought medical help (Steeman and Defever, 1998). Reasons such as lack of knowledge of the condition, a belief that urinary incontinence is part of normal ageing, fear of bothering a physician with such a problem, unawareness of available treatment and an acceptance of the symptoms have been reported (Shaw et al., 2001). Furthermore, lay people have a vague understanding and a lack of appropriate vocabulary (Mitteness, 1990), and the uncertainty about the nature of the symptoms and their gradual onset delay seeking medical help (Gannon et al., 2004). The help-seeking rate may be an indicator of lay people's understanding of the symptoms as well as knowledge about available treatment.

The aim was to compare urinary symptoms and their influence on daily life among elderly (75+) women and men in a sample that previously reported having incontinence and/or other urinary symptoms. A further aim was to find underlying structures of urinary symptoms and to identify symptoms which had an impact on seeking medical help and need of help in daily activities. 


\section{METHODS}

\subsection{Sample}

The sample consisted of 771 persons, 419 (54.3\%) women and 352 (45.7\%) men who answered a follow-up questionnaire to those in an age-stratified sample of 8500 persons, aged 75 years and above, who reported that during the past three months they had difficulties controlling urine and/or other urinary symptoms $(\mathrm{n}=1881)$ (Stenzelius et al., 2005). Two questions about symptoms from the urinary tract were addressed: "Do you have difficulties controlling urine?" and "Do you have other urinary symptoms?". The first of these questions was interpreted as signs of urinary incontinence according to the latest definition of the International Continence Society (ICS) (Abrams et al., 2002). The sample was divided into three groups depending on the answers in the first questionnaire: those with difficulties controlling urine (UI group, $n=423$, 276 women and 147 men) or other urinary symptoms (OU group, $\mathrm{n}=140,45$ women and 95 men) or having mixed symptoms (MS group, $\mathrm{n}=208,98$ women and 110 men). Questionnaires returned in unusable form were excluded from the analyses $(n=32)$.

The follow-up questionnaire was distributed about six months after the initial postal survey. Those identified as being independent (i.e., needed help in personal, instrumental or technical daily activities, $\mathrm{ADL}$, less than once a week or not at all) were sent the postal questionnaire with one reminder. The response rate among those was $65.4 \%(69.7 \%$ among those aged $75-79$ and 51.4\% among those aged 90+). Those identified as dependent (i.e. needing help in ADL once a week or more) were contacted by phone and interviewed in their own homes. This strategy was used to be sure of reaching the frailest persons. In all 645 persons were contacted and 141 persons agreed to the interview. The response rate was $21.9 \%$ (44.7\% among those aged $75-79$ and $11.1 \%$ among those aged $90+)$. Of the non-respondents in the group of dependent persons $(\mathrm{n}=504), 169(33.5 \%)$ were too weak or sick, $106(21 \%)$ did not want to participate, $52(10.3 \%)$ 
were not reachable, $16(3.2 \%)$ had language problems, $25(5 \%)$ were interviewed but gave inadequate answers and $136 \mathrm{did}$ not report any reason. The respondents were significantly younger $(p<0.0001)$, were more often married $(p<0.0001)$ and more of them lived at home $(\mathrm{p}<0.0001)$ compared with non-respondents. Furthermore, there were more men and fewer women $(\mathrm{p}<0.0001)$ in the respondent group. Additionally, the respondents reported fewer symptoms of memory problems $(p<0.0001)$, difficulty in walking $(p=0.021)$, fatigue $(p=0.016)$, low mood or depression ( $\mathrm{p}=0.002)$ compared with the non-respondents. Among the nonrespondents in the group of independent persons $(n=305), 59(19.3 \%)$ did not want to participate, 57 (18.6\%) had language problems, 47 (15.4\%) were too weak or sick, 20 (6.6\%) had memory problems or dementia and the rest did not give any reason. Respondents in the independent group were younger $(\mathrm{p}=0.005)$, lived together with another person $(\mathrm{p}=0.004)$, viewed life as bad/very bad ( $\mathrm{p}=0.011)$ to a greater extent than non-respondents.

\subsection{Instruments}

Urinary symptoms were investigated through the Bristol Female Lower urinary tract questionnaire BF-LUTS (Jackson et al., 1996) addressed to women and the International Continence Society male questionnaire, ICSmale addressed to men (Donovan et al., 1996). Those instruments were chosen because they had similar questions and comparisons were thus possible, although there was some terminology that differed and some questions that were gender-specific. The ICSmale questionnaire was professionally translated and retranslated in the ICS-BPH study (ICS- Benign Prostatic Hyperplasia study) and also checked by a lay advisor (Abrams et al., 1997). The BF-LUTS questionnaire was translated into Swedish and retranslated by a person with English as native language. Additionally an elderly woman was consulted as a lay advisor. The translation was compared with another translation performed by an industrial company and minor differences were adjusted. Although the questionnaires have been used in a Swedish context they have not been tested regarding reliability or validity. The questionnaires 
included questions about storage symptoms, voiding symptoms and bother caused by these symptoms. It also included questions about the influence of urinary symptoms on daily activities, daily life and life as a whole, which are considered by the constructors to be quality of life-related questions, condition-related and generic (Abrams et al., 1997). Most of the symptom questions had five response alternatives, i.e. never, occasionally (defined as less than one third of the time), sometimes (defined as between one and two thirds of the time), most of the time (defined as more than two thirds of the time) and all the time. The symptom questions were followed by a question about bother and had four response alternatives, i.e., not a problem, a bit of a problem, quite a problem, a serious problem. One question addressed help seeking as "Have you sought medical help for your urinary symptoms?” with Yes or No as response alternatives. Both ICSmale and BFLUTS questionnaires have been psychometrically tested in the original versions among younger populations and in patient populations (Donovan et al., 1996; Jackson et al., 1996; Abrams et al., 1997). The questionnaires have shown good validity, i.e. content, construct and criterion validity. Reliability, tested with Cronbach's alpha has shown values above 0.75 for the symptom and bother questions, which is acceptable for group comparisons (Polit, 1996).

\subsection{Statistics}

Questions from the BF-LUTS and ICSmale questionnaires with similar content, symptom and bother, were analysed as one variable. Questions that were not represented in both versions were excluded from the analysis as they were gender-specific, for example all questions about sex life (four in BF-LUTS and five in ICSmale), post-micturition dribble, total stop, the appearance of the stream, starting again during micturition, starting again within 15 minutes after micturition (in ICSmale). Data were analysed in groups according to the previously reported symptoms, i.e. those with difficulties controlling urine (UI group, $n=423$ ), and those with other urinary symptoms (OU group, $\mathrm{n}=140$ ) and those with mixed symptoms (MS group, $\mathrm{n}=208$ ).

Comparisons were calculated with Kruskal-Wallis test (Fig 1). Comparisons of symptoms and 
bother between men and women were calculated with Mann-Whitney U-test as data were at an ordinal level of scale (Table 2).

In order to find underlying structures of the symptom and bother questions, a principal component analyses with varimax rotation was performed with symptom and bother questions separately. Internal consistency was tested with Cronbach's alpha for items within each factor. The factor solution was based on eigen values above one (Hair et al., 1998) (Table 3). The result of the factor analyses was used to calculate mean values for symptom and bother scores of each factor as the sum of item score divided by the number of items in the factor. A low score indicated fewer and higher score more symptoms. Items with a four-graded scale were transformed into a three-graded scale to give similar scoring of all items. The "seldom" and "sometimes" answers were graded the same in the symptom questions (Table 4). Differences among women and men in factor mean values were calculated with One-way ANOVA test.

Two backward logistic regressions were performed with dependency (being dependent on help in $\mathrm{ADL}=1$, independent $=0$ ) and help seeking (have sought help $=1$, not sought help=0) as dependent variables. Gender, age group (with lowest age group as reference) mean values in factors of symptoms and daily life was included in both analyses as independent variables. Model fit was measured with Hosmer-Lemeshow goodness-of-fit test (where small chi-square and nonsignificant p-value indicated a good model) and Nagelkerke R square (Hair et al., 1998) (Table 5.). All statistical analyses was performed using the computer program SPSS (version 11.0).

\subsection{Ethics}

The study was approved by the Ethics Committee of the Medical Faculty at Lund University (LU 478-99). 


\section{RESULTS}

The mean age of the total sample was 81.4 years $\pm 5.1(\mathrm{SD}), 82.1$ year among women and 80.6 among men ( $\mathrm{p}<0.0001)$; $42.2 \%$ were aged $75-79$ years, $30.2 \%$ were $80-84$ years, $20.5 \%$ were 85-89 years and $7.1 \%$ were 90 years or above. Men were to a higher extent married $65.9 \%$, whilst women were widows $58.5 \%(\mathrm{p}<0.0001)$. Similarly, men lived together with someone (69.6\%) whilst women more often lived alone (68.5\%, $\mathrm{p}<0.0001)$. A total of 40 persons $(7.0 \%$ of women and $3.2 \%$ of men, $\mathrm{p}<0.0001$ ) lived in sheltered accommodation (Table 1 ).

Among all respondents only $16.6 \%$ had had their urinary problems for less than one year, $48.4 \%$ between one and five years and 35\% for ten years or more, with no difference between women and men $(p=0.07)$. Equally few women and men had not sought medical help for their problems, $58.7 \%$ vs. $54.5 \%(\mathrm{p}=0.266)$. More women had to change underwear or use protections because of leakage $(68.1 \%$ compared to $26 \%, \mathrm{p}<0.0001)$ and more men reported taking medications for their urinary problems compared to women $(30.4 \%$ vs. $22.9 \%, p=0.029)$ (Table $1)$.

Comparing symptoms in the groups who previously reported symptoms of incontinence and/or having other urinary problems besides urinary incontinence showed the highest prevalence of storage symptoms in the UI group $(\mathrm{p}<0.0001)$. Similarly, there was a significantly higher prevalence of voiding symptoms, i.e. strength of stream, strain to start and hesitance, in the OU group ( $\mathrm{p}=0.002, \mathrm{p}=0.003$ and $\mathrm{p}<0.0001$ respectively) while there were no significant differences between groups in symptoms of feeling incomplete emptying $(p=0.205)$. There were no significant differences between the groups in frequency, day or night time ( $\mathrm{p}=0.906$, and $\mathrm{p}=0.592$ respectively). Pain, bladder pain and burning sensation were more prevalent in the OU and MS groups ( $\mathrm{p}<0.0001$ and $\mathrm{p}=0.004$ respectively) than the UI group. The biggest influence on daily 
life was having to avoid places and situations due to urinary symptoms, which was similar in all groups regardless of which previous urinary symptom they had reported $(\mathrm{p}=0.449)$. Nor were there any differences in influence on social life $(p=0.426)$ and reducing fluid intake $(p=0.676)$ (Fig. 1).

Women reported significantly more (most of the time/all the time) of all storage symptoms $(\mathrm{p}<0.001)$ and in similar way men reported more frequency of daytime voiding and voiding symptoms $(\mathrm{p}<0.0001)$. Women and men reported similarly that $62.6 \%$ got up $1-2$ times a night and $28.3 \% 3$ times or more ( $\mathrm{p}=0.128)$; only around $10 \%$ did not get up at night to void. There were no gender differences in burning sensation $(\mathrm{p}=0.073)$ but women reported slightly more bladder pain $(\mathrm{p}=0.05)$ (Table 2$)$.

The factor analysis resulted in five categories for both symptom and bother questions (Table 3), which explained $62 \%$ of the total variance by the symptom questions and $69 \%$ by the bother questions. The factor analysis of the bother questions was not as clear as that of symptom questions in that hurry to reach the toilet in time loaded in the frequency factor. Furthermore, leakage before reaching the toilet and frequency of leakage loaded in two factors. The factor solution used in the further analysis was the symptom factor analysis and the factors were labelled storage, voiding, frequency, pain and daily life. Cronbach's alpha values for factors of symptom were $0.86,0.77,0.44,0.74$ and 0.83 and for factors of bother $0.86,0.87,0.82,0.73$ and 0.86 (Table 3).

Mean values of scores (1-3) within each factor showed similar results in symptom factors as in bother factors. However bother of frequency showed higher mean values compared to reported symptom score, but equal among women and men $(\mathrm{p}=0.261)$. Women reported more symptoms and bother in the storage factor $(\mathrm{p}<0.0001)$ and men more symptoms and bother in voiding 
factor $(\mathrm{p}<0.0001)$. Symptoms and bother in daily life were equally reported among women and men $(\mathrm{p}=.147$ and $\mathrm{p}=0.130$ respectively) (Table 4).

Predictors for help seeking were influence on daily life (OR 2.52), storage symptoms (OR 2.21) and pain symptoms (OR 2.1) when gender and age groups were controlled for. Predictors for dependency were high age (OR 2.64 (80-84 years) to $4.23(90+))$ and frequency symptoms (OR 3.24) (Table 5).

\section{DISCUSSION}

All urinary symptoms among elderly women and men need to be taken into account as those with other urinary symptoms than incontinence reported similar bother and influence on daily life compared to those reporting incontinence symptoms. Although storage symptoms like incontinence were more prevalent among women and voiding symptoms, i.e. hesitance, weak stream etc., more prevalent among men, all had similar influence on daily life. The voiding symptoms influenced social life, made people avoid places and situations as much as storage symptoms even though voiding symptoms were reported less bothersome. Frequent micturition day and night was bothering and the strongest predictor for dependency of all urinary symptoms. Influence of symptoms on daily life, storage and pain symptoms were the strongest predictors for seeking medical help.

A follow-up study of older persons with urinary symptoms from a population study is quite unique and gives an opportunity to gain deeper insight into response patterns to urinary problems. However, the risk of obtaining a skewed sample is obvious. In the initial study the oldest, those who were too weak or not worried about their health were under-represented (Stenzelius et al., 2005) even though special efforts had been made to include them. The dropout 
in this study comprised those who were too sick, had more other health complaints, more often women, living alone or unmarried, or men with poor economy. To sum up, this study consisted of the healthier part of the dependent and independent older persons with urinary problems, although quite a large sample (from 75 to 101 years) was reached. The result needs to be understood in the light of these limitations, yet some interesting conclusions can be made.

Both structured interviews and postal questionnaires were used in the data collection, which could be a threat to the external validity but could also increase the reliability (Kazdin, 1998). Sensitive questions are perhaps more difficult to omit face-to-face compared with a questionnaire (Khullar et al., 1998). On the other hand, the interview situation gave the possibility to ask and explain meaning of the questions. This approach was chosen in order to reach even those who were frail. However, bias due to this methodological approach must be valued together with the positive effect of reaching a difficult-to-reach population, i.e. those who were dependent on help from others or lived in sheltered housing.

The assessments used in the study were validated instruments, which have been used in population samples as well as patient samples and thus could assure the validity of the results (Donovan et al., 1996; Jackson et al., 1996). A limitation is the limited testing in older age groups. The questions were constructed to fit into clinically treatable symptoms such as urge, stress incontinence, obstruction and so on. The original version of BF-LUTS questionnaire was constructed from three symptoms groups, i.e. incontinence, voiding and storage and with Cronbach's alpha from 0.48 to 0.82 (Jackson et al., 1996). In a later development of the ICSmale questionnaire factor analysis was used in order to limit the amount of questions, resulting in two factors, voiding and incontinence (Donovan et al., 2000). The result of factor analysis in this study proved to have high Cronbach's alpha values, i.e. high reliability. This result did not separate incontinence from storage symptoms and showed other areas, frequency and pain, which 
confirm the use of factor analysis to understand the underlying structure of urinary symptoms as a complex rather than isolated phenomena. The differences in factoring could also be due to differences in urinary symptoms decreasing with age and may reflect symptoms from a patient rather than from a clinical perspective.

Analysing similar questions from female and male versions of the questionnaires together showed to be of value for comparing symptoms among women and men. This could be criticised first of all because some questions have different wordings in the male and female versions. For instance, traditional differences in the term "voiding" among men and women made it difficult to use the same word in the female and male questionnaire. Despite this, the value of using the same questions for this age group and in a population-based sample was that it enabled comparisons and conclusions about differences and similarities in women and men, which proved to be worthwhile as new results could be presented.

Although there were significant differences between women and men in storage and voiding symptoms, the similarities need to be highlighted as well. Research among older persons tends to focus on problems in the same way as in younger populations, for example as incontinence and voiding symptoms separately. However, in an elderly population the mixture of symptoms must be considered. Therefore the focus on male symptoms and female symptoms is important, just as it is important to reject the idea that urinary incontinence in these ages is an exclusively female problem. The influence on social life, avoidance of places and situations and view of life were similar among women and men, which indicates that men have as many limitations in their life as women have. Symptoms like day- and night-time frequency, which were similar in men and women, may influence daily life more than other voiding and storage symptoms do. This knowledge needs to taken into consideration when setting priorities in the treatment of urinary symptoms. 
The grouping based on initial questions from the population study was useful first of all to validate, in a sense, the results of the population study (Stenzelius et al., 2004). It may also clarify similarities in symptoms that may be more age-related as they were equally prevalent in the groups as well as among women and men. For instance, feelings of incomplete emptying could be explained by age-related muscular atrophy of the detrusor, which gives an irregular bladder contraction with residual urine as a consequence. Increased frequency day and night may be due to decreased bladder volume together with decreased ability to reabsorb secondary urine in the kidneys (Getliffe and Dolman, 1997). Irrespective of the origin of symptoms, gender, or which symptom predominated, the influence of the symptoms on daily life - such as reduction of fluid intake, avoiding places and situations, limitations in social life, and feelings of spending the rest of life with these symptoms - was similar. Hence, although it was possible to differentiate urinary symptoms in an elderly population, the risks of underestimating other aspects are obvious. Therefore a full exploration of urinary symptoms is worthwhile for understanding the complexity.

Older persons with difficulties reaching the toilet in time are vulnerable as there is an obvious risk of accidents and falls. Decreased mobility, one of the most prevalent symptoms in this population (Stenzelius et al., 2005), combined with urgency, frequent day and night voidings, are identified as risk factors for fall and used for assessment (Bakarich et al., 1997; Gowdy and Godfrey, 2003). For instance, a prospective study among women found a $26 \%$ increased risk of falls and a $34 \%$ increased risk of fractures among those with urge incontinence (Brown et al., 2000). However, the question used in these questionnaires has interpreted difficulties in reaching the toilet in time as urgency. However, research has not concentrated on differentiating urge symptoms from what is caused by outlying factors such as limited mobility in an elderly population, even though an effort to decrease symptoms such as urge, frequent toilet visiting as well as night-time voiding 
would be worthwhile to reduce complications such as falls and fractures as well as health care costs.

Only about $43 \%$ had sought medical help for their symptoms, although a majority of the respondents had had the symptoms for a long time, which indicates that there is a tendency to accommodate in everyday life. Several reasons for not seeking medical help have been reported (Cunningham-Burley et al., 1996; Steeman and Defever, 1998; Roe et al., 1999; Shaw et al., 2001; Gannon et al., 2004), mainly due to limited knowledge about function and dysfunction of the urinary tract and available treatment among older persons, but also among professionals. Proper health education would probably eliminate a lot of misunderstanding among those suffering from urinary symptoms and also among health care providers. One solution could be to simplify the description of urinary symptoms among older persons, such as too big or too small resistance of urinary control or as bladder control disturbances (Mitteness and Barker, 1995). Then all symptoms would be included without value, which would help in the health education that is needed in this population.

It may be an easier decision to visit a doctor for a more urgent symptom than for a symptom which has been there for a long time, as storage symptoms and bladder pain was the strongest indicator for seeking medical help. It is perhaps a common belief that pain may be dangerous while other symptoms from the urinary tract are part of life. The effect on daily life was more important than other urinary symptoms on seeking medical help, which seems logical, although few if any have shown this before. In order to convince people to seek medical help at an earlier stage, development of assessments is necessary. This may help people to identify when the influence of urinary symptoms on daily life has come to a point where it is necessary to seek medical advice. 
Reduction of night-time incontinence episodes may keep older persons independent or delay dependency, as this was the symptom that most strongly predicted dependency. There is a lack of other studies which have explicitly investigated risk factors among the urinary symptoms for dependency/need of help in daily activities or institutionalisation. These results therefore cannot be compared. However, this result indicates a need for further studies in this area, especially as it is known that dependency has proved to be associated with lowered quality of life (Stenzelius et al., 2005). It is also necessary in a time where the oldest old are increasing in number and health care costs have to be reduced.

\section{CONCLUSION}

Men and women reported similar influence on social life and avoiding places and situations due to their urinary symptoms, although men reported more of voiding symptoms and women more storage symptoms such as incontinence. However, the mixture of symptoms and similarities among men and women indicates a need to look at urinary symptoms from a wider perspective in both sexes. Obviously, there is a need to encourage older persons to seek medical help and to get treatment or alleviations for the symptoms that give most bother and indicate dependency, such as reduction of day- and night-time frequency and being able to reach the toilet in time without leakage.

\section{ACKNOWLEDGEMENTS}

This study was supported by grants from The Vårdal Foundation, Region Skåne, Greta Ekholm’s Foundation and Vetenskapsrådet. The authors wish to thank those who kindly responded to the 
questionnaires, thus making the study possible. We also thank our colleagues Magdalena Andersson, Gunilla Borglin, Anna Ekwall, Ylva Hellström, Ann-Christin Janlöv, Ulf Jakobsson and Bibbi Thomé who were involved in the data collection. Thanks to Pia Teleman who participated in the translations process of the BF-LUTS questionnaire. Thanks also to Per Nyberg for help and advice in statistical matters and to Alan Crozier, PhD, for help with the English language. 


\section{REFERENCES}

Abrams, P., Donovan, J. L., de la Rosette, J. J., Schafer, W., 1997. International Continence Society "Benign Prostatic Hyperplasia" Study: background, aims, and methodology. Neurourol. Urodyn. 16, 79-91.

Abrams, P., Cardozo, L., Fall, M., Griffiths, D., Rosier, P., Ulmsten, U., van Kerrebroeck, P., Victor, A., Wein, A., 2002. The standardisation of terminology of lower urinary tract function: report from the Standardisation Sub-committee of the International Continence Society. Neurourol. Urodyn. 21, 167-178.

Aggazzotti, G., Pesce, F., Grassi, D., Fantuzzi, G., Righi, E., De Vita, D., Santacroce, S., Artibani, W., 2000. Prevalence of urinary incontinence among institutionalized patients: a cross-sectional epidemiologic study in a midsized city in northern Italy. Urology 56, 245-249.

Araki, I., Zakoji, H., Komuro, M., Furuya, Y., Fukasawa, M., Takihana, Y., Takeda, M., 2003. Lower urinary tract symptoms in men and women without underlying disease causing micturition disorder: a cross-sectional study assessing the natural history of bladder function. J. Urol. 170, 1901-1904.

Bakarich, A., McMillan, V., Prosser, R., 1997. The effect of a nursing intervention on the incidence of older patient falls. Aust. J. Adv. Nurs. 15, 26-31.

Brown, J. S., Vittinghoff, E., Wyman, J. F., Stone, K. L., Nevitt, M. C., Ensrud, K. E., Grady, D., 2000. Urinary incontinence: does it increase risk for falls and fractures? Study of Osteoporotic Fractures Research Group. J. Am. Geriatr. Soc. 48, 721-725.

Cunningham-Burley, S., Allbutt, H., Garraway, W. M., Lee, A. J., Russell, E. B., 1996. Perceptions of urinary symptoms and health-care-seeking behaviour amongst men aged 40-79 years. Br. J. Gen. Pract. 46, 349-352.

Donovan, J. L., Abrams, P., Peters, T. J., Kay, H. E., Reynard, J., Chapple, C., De La Rosette, J. J., Kondo, A., 1996. The ICS-'BPH' Study: the psychometric validity and reliability of the ICSmale questionnaire. Br. J. Urol. 77, 554-562.

Donovan, J. L., Peters, T. J., Abrams, P., Brookes, S. T., De La Rosette, J. J., Schafer, W., 2000. Scoring the short form ICSmaleSF questionnaire. International Continence Society. J. Urol. 164, 1948-1955.

Gannon, K., Glover, L., O'Neill, M., Emberton, M., 2004. Men and chronic illness: a qualitative study of LUTS. J. Health. Psychol. 9, 411-420.

Getliffe, K., Dolman, M., 1997. Promoting Continence - A Clinical and Research Resource. Bailliére Tindall, London.

Gowdy, M., Godfrey, S., 2003. Using tools to assess and prevent inpatient falls. Jt. Comm. . Qual. Saf. 29, 363-368.

Hair, J. F., Anderson, R.E., Tatham, R.L., Black, W.C., 1998. Multivariate Data Analysis. 5th ed. Prentice-Hall International, London.

Hansen, B. J., Flyger, H., Brasso, K., Schou, J., Nordling, J., Thorup Andersen, J., Mortensen, S., Meyhoff, H. H., Walter, S., Hald, T., 1995. Validation of the self-administered Danish Prostatic Symptom Score (DAN-PSS-1) system for use in benign prostatic hyperplasia. Br. J. Urol. 76, 451-458.

Jackson, S., Donovan, J., Brookes, S., Eckford, S., Swithinbank, L., Abrams, P., 1996. The Bristol Female Lower Urinary Tract Symptoms questionnaire: development and psychometric testing. Br. J. Urol. 77, 805-812.

Kay, L., Stigsby, B., Brasso, K., Mortensen, S. O., Munkgaard, S., 1999. Lower urinary tract symptoms--a population survey using the Danish Prostatic Symptom Score (DAN-PSS) questionnaire. Scand. J. Urol. Nephrol. 33, 94-99. 
Kazdin, A. E., 1998. Reseach Design in Clinical Pschology. Third edition. Allyn and Bacon, Boston.

Khullar, V., Damiano, R., Toozs-Hobson, P., Cardozo, L., 1998. Prevalence of faecal incontinence among women with urinary incontinence. Br. J. Obstet. Gynaecol. 105, 1211-1213.

Maggi, S., Minicuci, N., Langlois, J., Pavan, M., Enzi, G., Crepaldi, G., 2001. Prevalence rate of urinary incontinence in community-dwelling elderly individuals: the Veneto study. J. Gerontol. A. Biol. Sci. Med. Sci. 56, M14- M18.

Meyhoff, H. H., Hald, T., Nordling, J., Andersen, J. T., Bilde, T., Walter, S., 1993. A new patient weighted symptom score system (DAN-PSS-1). Clinical assessment of indications and outcomes of transurethral prostatectomy for uncomplicated benign prostatic hyperplasia. Scand. J. Urol. Nephrol. 27, 493-499.

Mitteness, L. S., 1990. Knowledge and beliefs about urinary incontinence in adulthood and old age. J. Am. Geriatr. Soc. 38, 374-378.

Mitteness, L. S., Barker, J. C., 1995. Stigmatizing a "normal" condition: urinary incontinence in late life. Med. Anthropol. Q. 9, 188-210.

Nakanishi, N., Tatara, K., Shinsho, F., Murakami, S., Takatorige, T., Fukuda, H., Nakajima, K., Naramura, H., 1999. Mortality in relation to urinary and faecal incontinence in elderly living at home. Age Ageing 28, 301-306.

Noelker, L., 1987. Incontinence in elderly cared for by family. The Gerontologist. 27, 194-200.

Ouslander, J. G., Buxton, W. G., Al-Samarrai, N. R., Cruise, P. A., Alessi, C., Schnelle, J. F., 1998. Nighttime urinary incontinence and sleep disruption among nursing home residents. J. Am. Geriatr. Soc. 46, 463-466.

Polit, D. F., 1996. Data Analysis \& Statistics for Nursing Research. Prentice-Hall International, New Yersey. p.249.

Roe, B., Doll, H., Wilson, K., 1999. Help seeking behaviour and health and social services utilisation by people suffering from urinary incontinence. Int. J. Nurs. Stud. 36, 245253.

Schatzl, G., Temml, C., Schmidbauer, J., Dolezal, B., Haidinger, G., Madersbacher, S., 2000. Cross-sectional study of nocturia in both sexes: analysis of a voluntary health screening project. Urology 56, 71-75.

Schatzl, G., Temml, C., Waldmuller, J., Thurridl, T., Haidinger, G., Madersbacher, S., 2001. A comparative cross-sectional study of lower urinary tract symptoms in both sexes. Eur. Urol. 40, 213-219.

Schmidbauer, J., Temml, C., Schatzl, G., Haidinger, G., Madersbacher, S., 2001. Risk factors for urinary incontinence in both sexes. Analysis of a health screening project. Eur. Urol. 39, 565-570.

Shaw, C., Tansey, R., Jackson, C., Hyde, C., Allan, R., 2001. Barriers to help seeking in people with urinary symptoms. Fam. Pract. 18, 48-52.

Steeman, E., Defever, M., 1998. Urinary incontinence among elderly persons who live at home: a literature review. Nurs. Clin. North. Am. 33, 441-455.

Stenzelius, K., Mattiasson, A., Hallberg, I. R., Westergren, A., 2004. Symptoms of urinary and faecal incontinence among men and women $75+$ in relations to health complaints and quality of life. Neurourol. Urodyn. 23, 211-222.

Stenzelius, K., Westergren, A., Thorneman, G., Hallberg, I. R., 2005. Patterns of health complaints among people $75+$ in relation to quality of life and need of help. Arch. Gerontol. Geriatr. 40, 85-102.

Stoddart, H., Donovan, J., Whitley, E., Sharp, D., Harvey, I., 2001. Urinary incontinence in older people in the community: a neglected problem? Br. J. Gen. Pract. 51, 548-552.

Wyman, J. F., Harkins, S. W., Choi, S. C., Taylor, J. R., Fantl, J. A., 1987. Psychosocial impact of urinary incontinence in women. Obstet. Gynecol. 70, 378-381. 


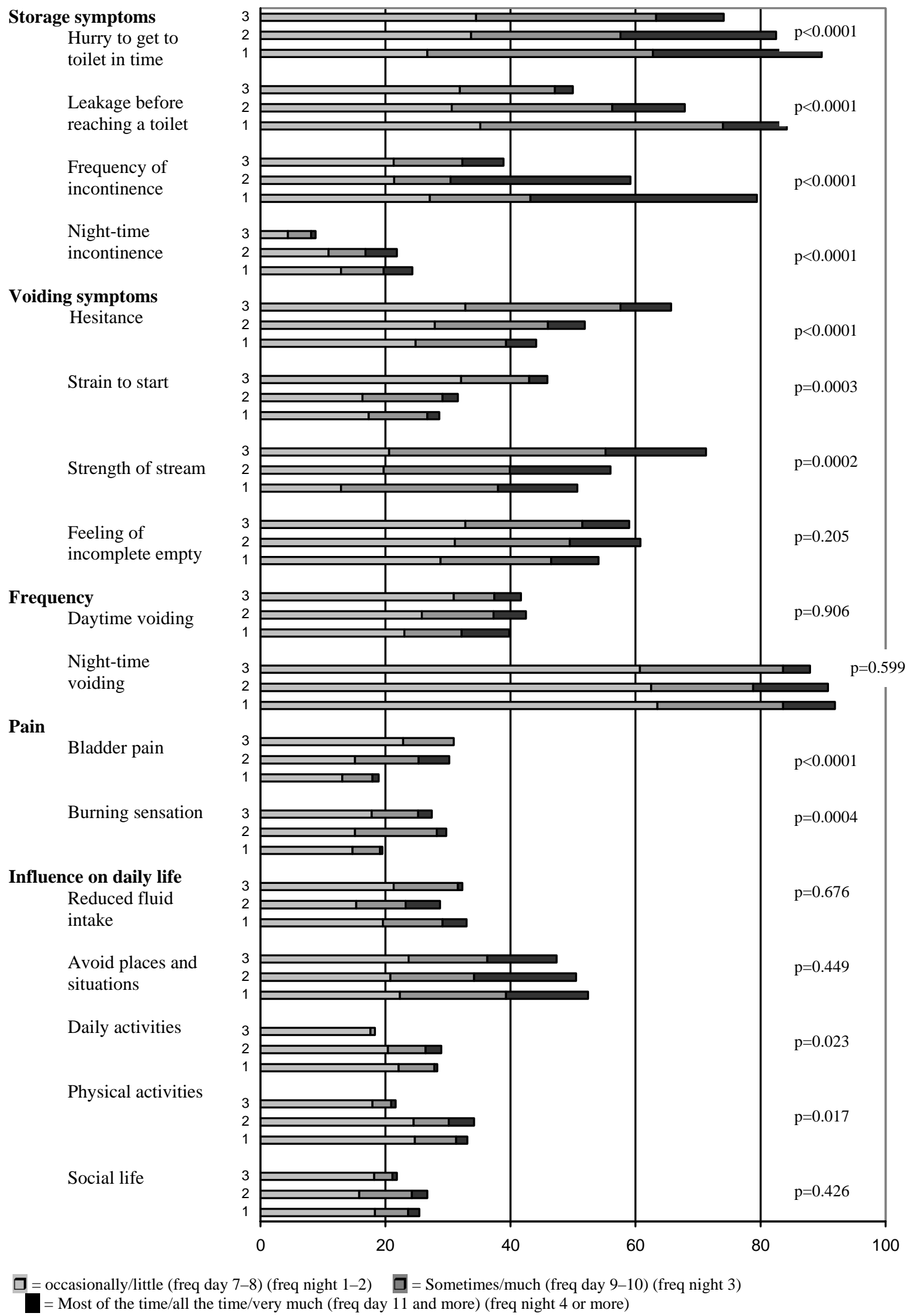

Figure 1. Prevalence (\%) and grade of symptoms in the group reporting symptoms of incontinence (1), symptoms of both urinary incontinence and other urinary symptoms (2) and those reported to have other urinary symptoms except incontinence (3). P-values (Kruskal-Wallis) differences between the three groups. 
Table 1. Socioeconomic description of the sample, help seeking and medications among women and men (\%)

\begin{tabular}{|c|c|c|c|c|}
\hline & $\begin{array}{r}\text { All } \\
\mathrm{N}=771\end{array}$ & $\begin{array}{r}\text { Women } \\
n=419\end{array}$ & $\begin{array}{r}\text { Men } \\
\mathrm{n}=352\end{array}$ & P-value \\
\hline Age groups & & & & $<0.0001$ \\
\hline 75-79 years & 42.2 & 37.5 & 47.7 & \\
\hline 80-84 years & 30.2 & 30.5 & 29.8 & \\
\hline 85-89 years & 20.5 & 21.7 & 19.0 & \\
\hline $90+$ years & 7.1 & 10.3 & 3.4 & \\
\hline Civil status & & & & $<0.0001$ \\
\hline Married & 45.5 & 28.4 & 65.9 & \\
\hline Widowed/divorced/single & 54.5 & 71.6 & 44.1 & \\
\hline Living conditions & & & & $<0.0001$ \\
\hline Alone & 51.1 & 68.5 & 30.4 & \\
\hline Together with someone & 48.9 & 31.5 & 69.6 & \\
\hline Living place & & & & $<0.0001$ \\
\hline Community & 94.8 & 93.0 & 96.8 & \\
\hline Sheltered housing & 5.2 & 7.0 & 3.2 & \\
\hline \multicolumn{5}{|l|}{ Dependent in } \\
\hline PADL & 9.0 & 11.5 & 6.0 & 0.0009 \\
\hline IADL & 14.8 & 17.0 & 12.2 & 0.063 \\
\hline Time with urinary symptoms & & & & 0.077 \\
\hline$<2$ years & 30.2 & 26.2 & 34.7 & \\
\hline $2-5$ years & 34.8 & 35.9 & 33.5 & \\
\hline$>5$ years & 35.0 & 47.9 & 31.8 & \\
\hline Sought medical help & & & & 0.266 \\
\hline Yes & 43.3 & 41.3 & 45.5 & \\
\hline No & 56.7 & 58.7 & 54.5 & \\
\hline Forced to change underwear/use protections & & & & $<0.0001$ \\
\hline Yes & 51.2 & 68.1 & 26.0 & \\
\hline No & 48.8 & 31.9 & 74.0 & \\
\hline Taking medications for urinary symptoms & & & & 0.029 \\
\hline Yes & 26.2 & 22.9 & 30.4 & \\
\hline No & 73.8 & 77.1 & 69.6 & \\
\hline
\end{tabular}

Significance tested with Chi-square test and Mann-Whitney U-test. 
Table 2. Prevalence of urinary storage, voiding, frequency and pain symptoms and reported symptom influence on daily life among women and men (\%)

\begin{tabular}{|c|c|c|c|c|}
\hline Age, mean (SD) & $\begin{array}{r}\text { All } \\
\mathrm{N}=771 \\
81.4(5.1)\end{array}$ & $\begin{array}{r}\text { Women } \\
n=419 \\
82.1(5.4)\end{array}$ & $\begin{array}{r}\text { Men } \\
n=352 \\
80.6(4.5)\end{array}$ & P-value \\
\hline \multicolumn{5}{|l|}{ Storage symptoms } \\
\hline Hurry to get to toilet in time & & & & $<0.0001$ \\
\hline Occasionally/sometimes & 61.3 & 54.4 & 69.5 & \\
\hline Most of the time/all the time & 23.5 & 32.2 & 13.2 & \\
\hline Leakage before reaching the toilet & & & & $<0.0001$ \\
\hline Occasionally/sometimes & 64.5 & 71.2 & 56.5 & \\
\hline Most of the time/all the time & 9.2 & 12.9 & 4.9 & \\
\hline Night-time incontinence & & & & $<0.0001$ \\
\hline Occasionally/sometimes & 16.7 & 21.4 & 11.4 & \\
\hline Most of the time/all the time & 3.8 & 6.0 & 1.2 & \\
\hline Frequency of incontinence & & & & $<0.0001$ \\
\hline Once a week or less & 24.7 & 22.9 & 26.7 & \\
\hline 2-3 times a week & 13.3 & 15.0 & 11.4 & \\
\hline Daily/several times a day & 28.6 & 40.7 & 14.4 & \\
\hline Stress incontinence* & & & & $<0.0001$ \\
\hline Occasionally/sometimes & $51.8 *$ & $60.5^{*}$ & $38.5 *$ & \\
\hline Most of the time/all the time & $14.8 *$ & $22.9 *$ & $2.2 *$ & \\
\hline Incontinence without reason* & & & & 0.001 \\
\hline Occasionally/sometimes & $38.2 *$ & $40.3 *$ & $35.0 *$ & \\
\hline Most of the time/all the time & $6.2 *$ & $8.6 *$ & $2.5 *$ & \\
\hline Size of leakage* & & & & $<0.0001$ \\
\hline Soaked or wet underwear & $68.8^{*}$ & $75.3 *$ & $59.3 *$ & \\
\hline Flowing, soaking other cloths & $3.9 *$ & $5.2 *$ & $1.8^{*}$ & \\
\hline \multicolumn{5}{|l|}{ Voiding symptoms } \\
\hline Hesitance & & & & $<0.0001$ \\
\hline Occasionally/sometimes & 44.4 & 32.4 & 58.4 & \\
\hline Most of the time/always & 5.7 & 3.5 & 8.4 & \\
\hline Strain to start & & & & $<0.0001$ \\
\hline Occasionally/sometimes & 30.4 & 21.1 & 41.3 & \\
\hline Most of the time/always & 2.3 & 2.2 & 2.4 & \\
\hline Strength of stream & & & & $<0.0001$ \\
\hline Occasionally/sometimes weak & 41.8 & 30.1 & 55.5 & \\
\hline Often/always weak & 14.2 & 7.9 & 21.5 & \\
\hline Feeling of incomplete emptying & & & & $<0.0001$ \\
\hline Occasionally/sometimes & 48.3 & 40.8 & 56.7 & \\
\hline Most of the time/always & 8.5 & 7.8 & 9.2 & \\
\hline \multicolumn{5}{|l|}{ Frequency } \\
\hline Daytime voiding & & & & 0.001 \\
\hline $7-8$ & 25.3 & 23.2 & 27.8 & \\
\hline $9-12$ & 13.0 & 10.5 & 16.1 & \\
\hline 13 or more & 2.6 & 1.7 & 3.7 & \\
\hline Night-time voiding & & & & 0.128 \\
\hline $1-2$ & 62.6 & 64.2 & 60.8 & \\
\hline 3 and more & 28.3 & 25.8 & 31.2 & \\
\hline \multicolumn{5}{|l|}{ Pain } \\
\hline Bladder pain & & & & 0.050 \\
\hline Occasionally/sometimes & 22.3 & 22.4 & 22.1 & \\
\hline Often/always & 1.9 & 2.7 & .9 & \\
\hline Burning sensation & & & & 0.073 \\
\hline Occasionally/sometimes & 22.6 & 25.2 & 19.7 & \\
\hline Often/always & 1.1 & 1.3 & .9 & \\
\hline
\end{tabular}

\section{Daily life}


Reduction of fluid intake

Occasionally/sometimes

Often/always

Avoid places and situation

Occasionally/sometimes

Often/always

Ability to complete daily activities

Little

Much/very much

Ability to perform physical activities

Little

Much/very much

Influence on social life

Little

Much/very much

Influence on whole life

Little

Much/very much

$\begin{array}{rrrr}27.9 & 27.3 & 28.5 & \\ 3.7 & 5.1 & 2.3 & \\ & & & 0.352 \\ 37.6 & 35.5 & 39.9 & \\ 13.8 & 13.6 & 13.9 & \\ & & & <0.0001 \\ 21.0 & 25.8 & 15.4 & \\ 5.5 & 6.8 & 3.9 & 0.051 \\ & & & \\ 23.5 & 26.8 & 19.7 & 0.332 \\ 7.6 & 8.4 & 6.6 & \\ & & & \\ 17.5 & 15.1 & 20.3 & \\ 7.2 & 7.4 & 7.1 & \\ & & & \\ 40.1 & 37.4 & 43.2 & \\ 13.0 & 14.4 & 11.6 & \end{array}$

Significance measured with Mann-Whitney U-test. *Answered by those who answered the question on frequency of leakage, i.e. \% of those with incontinence. 
Table. 3a. Factor analysis of symptom questions in the BF-LUTS and ICSmale questionnaires together.

\begin{tabular}{|c|c|c|c|c|c|c|}
\hline & Storage & Daily life & Voiding & Frequency & Pain/burning & Communalities \\
\hline Leakage before reaching toilet & 0.814 & & & .437 & & 0.739 \\
\hline Frequency of incontinence & 0.847 & & & & & 0.756 \\
\hline Stress incontinence & 0.702 & & & & & 0.557 \\
\hline Leakage without reason & 0.690 & & & & & 0.602 \\
\hline Size of leakage & 0.766 & & & & & 0.600 \\
\hline Leakage during sleep & 0.607 & & & & & 0.426 \\
\hline Hurry to reach toilet in time & 0.561 & & & & & \\
\hline Reduced fluid intake & & 0.554 & & & & 0.346 \\
\hline Influences daily activities & & 0.688 & & & & 0.575 \\
\hline Avoidance of places & & 0.688 & & & & 0.613 \\
\hline Influences physical activities & & 0.812 & & & & 0.733 \\
\hline Social life & & 0.775 & & & & 0.684 \\
\hline Whole life & & 0.698 & & & & 0.698 \\
\hline Hesitance & & & 0.837 & & & 0.715 \\
\hline Strain to start & & & 0.756 & & & 0.651 \\
\hline Strength of stream & & & 0.748 & & & 0.605 \\
\hline Incomplete emptying & & & 0.636 & & & 0.533 \\
\hline Frequency daytime & & & & 0.731 & & 0.622 \\
\hline Frequency night time & & & & 0.656 & & 0.530 \\
\hline Bladder pain & & & & & 0.795 & 0.735 \\
\hline Burning sensation & & & & & 0.806 & 0.753 \\
\hline Eigen value & 6.75 & 2.61 & 1.82 & 1.31 & 1.14 & \\
\hline $\begin{array}{l}\text { Explained variance \% } \\
\text { Total: } 61.94 \%\end{array}$ & 30.68 & 11.84 & 8.27 & 5.95 & 5.19 & \\
\hline Cronbach's alpha & 0.86 & 0.83 & 0.77 & 0.44 & 0.74 & \\
\hline
\end{tabular}

How often do you urinate daytime (hourly) did not fit into the analysis.

Table 3b. Factor analysis of distress questions in the BF-LUTS and ICSmale questionnaires together.

\begin{tabular}{|c|c|c|c|c|c|c|}
\hline Distress from ... & Daily life & Storage & Voiding & Frequency & Pain/burning & Communalities \\
\hline Leakage before reaching toilet & & 0.670 & & 0.526 & & 0.765 \\
\hline Frequency of incontinence & & 0.742 & & 0.496 & & 0.841 \\
\hline Stress incontinence & & 0.750 & & & & 0.688 \\
\hline Leakage without reason & & 0.757 & & & & 0.717 \\
\hline Leakage during sleep & & 0.664 & & & & 0.568 \\
\hline Hurry to reach toilet in time & & & & 0.725 & & 0.785 \\
\hline Reduces fluid intake & 0.548 & & & & & 0.454 \\
\hline Influences daily activities & 0.727 & & & & & 0.707 \\
\hline Avoidance of places & 0.671 & & & & & 0.617 \\
\hline Influences physical activities & 0.854 & & & & & 0.833 \\
\hline Social life & 0.784 & & & & & 0.712 \\
\hline Hesitance & & & 0.781 & & & 0.741 \\
\hline Strain to start & & & 0.803 & & & 0.707 \\
\hline Strength of stream & & & 0.848 & & & 0.772 \\
\hline Incomplete emptying & & & 0.723 & & & 0.650 \\
\hline Frequency daytime & & & & 0.721 & & 0.748 \\
\hline Frequency night time & & & & 0.656 & & 0.625 \\
\hline Bladder pain & & & & & 0.831 & 0.812 \\
\hline Burning sensation & & & & & 0.788 & 0.776 \\
\hline Eigen value & 8.315 & 2.071 & 1.444 & 1.035 & 1.009 & \\
\hline $\begin{array}{l}\text { Explained variance \% } \\
\text { Total. } 6937 \%\end{array}$ & 41.53 & 10.36 & 7.22 & 5.17 & 5.04 & \\
\hline Cronbach's alpha & 0.86 & 0.87 & 0.87 & 0.82 & 0.73 & \\
\hline
\end{tabular}


Table 4. Mean scores for factors of urinary symptoms and distress and their influence on daily life among women and men

\begin{tabular}{|c|c|c|c|c|c|c|}
\hline & \multicolumn{3}{|c|}{ Symptom score } & \multicolumn{3}{|c|}{ Distress score } \\
\hline & $\begin{array}{r}\text { Women } \\
n=419\end{array}$ & $\begin{array}{r}\text { Men } \\
\mathrm{n}=352\end{array}$ & p-value & $\begin{array}{r}\text { Women } \\
n=419\end{array}$ & $\begin{array}{r}\text { Men } \\
\mathrm{n}=352\end{array}$ & p-value \\
\hline Voiding & $0.40(.46)$ & $0.75(.50)$ & $<0.0001$ & $0.29(.50)$ & $0.49(.58)$ & $<0.0001$ \\
\hline Frequency & $0.37(.40)$ & $0.48(.44)$ & 0.001 & $0.70(.76)$ & $0.76(.75)$ & 0.261 \\
\hline Pain & $0.27(.44)$ & $0.22(.39)$ & 0.092 & $0.28(.53)$ & $0.20(.43)$ & 0.042 \\
\hline
\end{tabular}

Significance measured with One-way ANOVA.

Table 5. Predictor for dependency and help seeking of the urinary symptom and daily life factors.

\begin{tabular}{|c|c|c|c|c|c|c|}
\hline & \multicolumn{3}{|c|}{ Dependency } & \multicolumn{3}{|c|}{ Help seeking } \\
\hline & Exp B & $(95 \% \mathrm{CI})$ & P-value & Exp B & $95 \%$ CI & P-value \\
\hline Gender & - & - & NS & - & - & NS \\
\hline \multicolumn{7}{|l|}{ Age group } \\
\hline $80-84$ & 1.57 & $0.84-2.98$ & 0.158 & - & - & NS \\
\hline $85-89$ & 2.64 & $1.38-5.04$ & 0.003 & - & - & NS \\
\hline $90+$ & 4.23 & $1.80-9.89$ & 0.001 & - & - & NS \\
\hline Storage symptom factor & & & & 2.21 & $1.48-3.30$ & $<0.0001$ \\
\hline Voiding symptom factor & .52 & $0.30-0.89$ & 0.019 & - & - & NS \\
\hline Frequency symptom factor & 3.24 & $1.82-5.76$ & $<0.0001$ & - & - & NS \\
\hline Pain symptom factor & & & & 2.10 & $1.29-3.44$ & 0.003 \\
\hline Daily life factor & & & & 2.52 & $1.57-4.03$ & $<0.0001$ \\
\hline \multicolumn{7}{|l|}{ Strength of model } \\
\hline Hosmer-Lemeshow, Chi-square & 11.16 & & 0.193 & 12.02 & & 0.150 \\
\hline Nagelkerke R square & 0.130 & & & 0.173 & & \\
\hline
\end{tabular}

NS = non significant 